\title{
RAIINSTEK

\section{RANCANG BANGUN SISTEM INFORMASI STUDIO RENTAL REKAMAN GZ STUDIO MUSIK BERBASIS WEB}

\author{
Dimas Handoyo Kusuma Pradana ${ }^{1}$, Wiwin Kusniwardi ${ }^{2}$ \\ Sistem Informasi, Universitas Kanjuruhan Malang ${ }^{1,2}$ \\ dimasdegasperis@gmail.com ${ }^{1}$, jacobwin@gmail.com ${ }^{2}$
}

\begin{abstract}
Abstrak. GZ Studio Musik pelayanan yang bergerak di bidang jasa penyewaan studio musik. Selama ini masih menggunakan sistem booking dan penjadwalan secara manual.Berdasarkan kebutuhan tersebut,dirancang sebuah sistem informasi penyewaan pada GZ Studio Musik berupa aplikasi berbasis web dengan metode waterfall dan menggunakan model Software Development Life Cycles (SDLC). Tujuan dalam penelitian rancang bangun ini membangun sistem informasi berbasis web agar memudahkan Customer dan Pemilik GZ Studio Musik dalam memperoleh informasi Booking studio, penjadwalan dan administrasi yang baik dan praktis.Penelitian Sistem informasi yang dibangun di GZ Studio Musik mendapat hasil Penilaian User Acceptance Test (UAT) dengan rata rata 90,35\%
\end{abstract}

Kata Kunci: Sistem Informasi, Web, Penyewaan, Booking, Waterfall.

\section{PENDAHULUAN}

Proses pesan untuk rekaman dan sewa alat di GZ Studio Musik dilakukan dengan cara pelanggan datang melakukan pendaftaran dan bayar uang muka secara langsung di tempat, hal ini dilakukan agar tanggal yang sudahdi pesan dapat di konfirmasi.Pelanggan dari GZ Studio Musik kebanyakan datang dari luar Malang, kebanyakan pemesanan dilakkan melalui telepon diluar jam kerja, sehingga berakibat terjadinya bentrok tanggal pemesanan dan kadang kadang pelanggan tidak menerima tanggapan atau informasi yang jelas menenai studio. Tujuan dalam penelitian rancang bangun ini untuk membangun sistem informasi berbasis website agar memudahkan Customer dan Pemilik GZ Studio Musik dalam memperoleh informasi tentang Booking studio, penjadwalan, laporan keuangan atau administrasi.

Penelitian sebelumnya tentang perancangan sistem informasi penyewaan studio recording sudah pernah dilakukan oleh Debi Arsianti ,2016.Tetapi dalam perancangan sistem yang telah dibuat masih terdapat kekurangan yaitu belum adanya pengembangan sistem yang terintegrasi degan internet atau belum bisa di akses secara online. Bagaimana membuat suatu Sistem Informasi Berbasis Web yang dapat membantu administrasi GZ Studio Musik untuk pengelolaan booking dan penyewaan alat music yang bisa melengkapi dari peneliti sebelumnya.

Berdasarkan permasalahan di atas, penulis termotivasi untuk melakukan penelitian di studio rekaman musik GZ Studio Musik, dan bermaksud untuk membuat "Rancang Bangun Sistem Informasi Studio Rental Rekaman GZ Studio Musik Berbasis WEB”.

\section{METODE PENELITIAN}

Model yang digunakan dalam pengembangan produk penelitian adalah model Software Development Life Cycles (SDLC). Model tersebut merupakan tahapan-tahapan pekerjaan yang dilakukan oleh analis sistem dan programmer dalam membangun sistem informasi (Dwanoko, 2016). Hal ini menggambarkan pendekatan yang sistematis dan juga berurutan pada pengembangan perangkat lunak, dimulai dengan spesifikasi kebutuhan pengguna lalu berlanjut melalui tahapan-tahapan perencanaan (planning), permodelan (modeling), konstruksi (construction), serta penyerahan sistem ke para pelanggan/pengguna (deployment), yang diakhiri dengan dukungan pada perangkat lunak lengkap yang dihasilkan (Pressman, 2015). Tahapan metode waterfall dapat dilihat pada gambar di bawah ini. 


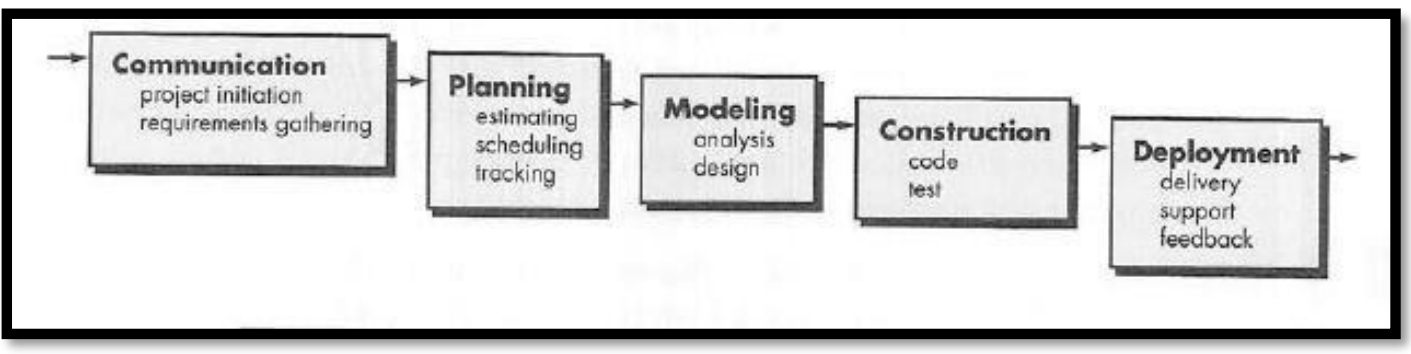

\section{Subjek Penelitian}

Gambar 1. Model Waterfall (Pressman, 2015)

Subyek uji coba merupakan aktor yang terlibat didalam sistem. Subjek melakukan aktivitas ujicoba terhadap sistem yang telah dibuat sesuai dengan fungsi tersendiri. Didalam penelitian ini terdapat 3 aktor yang terlibat, yaitu admin, 30 Pelanggan/ customer.

\section{Instrumen Pengumpulan Data}

Pada penelitian ini telah dipilih instrumen pengumpulan data yang tepat sesuai kebutuhan yang ada.Antaralain sebagai Berikut :

1. Observasi

Dalam hal ini peneliti melakukan pengamatan langsung pada tempat penelitian untuk menganalisis data sistem informasi yang diterapkan di GZ Studio Musik Kepanjen _ Malang, kemudian peneliti melakukan perancangan sistem prediksi sistem booking/Administrasi sesuai hasil analisis yang dilakukan.

\section{Wawancara}

Dalam penelitian ini kegiatan wawancara dilakukan dengan mengajukan pertanyaan ke manajer, admin di GZ Studio Musik.Untuk memeproleh informasi tentang permasalahan dan kebutuhan di lapangan.Peneliti menggunakan wawancara tidak terstruktur kepada Manajer,Admin,bahkankepada beberapa pelanggan/Customer.

3. Dokumentasi

Penggunaan metode dokumentasi ini bertujuan untuk memperkuat dan mendukung informasi yang didapatkan dari hasil observasi dan wawancara.

\section{Teknik Analisis Data}

Teknik analisis data yang digunakan dalampenelitian ini menggunakan User Acceptance Test (UAT), Perhitungan UAT dimulai dari jumlah data yang di dapat diolah dengan cara mengalihkan setiap poin jawaban dengan bobot yang telah ditentukan sesuai dengan tabel bobot nilai jawaban.

\section{HASIL DAN PEMBAHASAN}

Desain awal produk dalam penelitian dalam prosesnya perancangannya peneliti menggunakan model Waterfall. Terdapat lima tahapan yakni:

\section{Comummunication}

Observasi dan Wawancara bertujuan untuk mencari tahu permasalahan yang ada pada dalam Proses Booking, penjadwalan dan laporan keuangan di GZ Studio Musik.

\section{Kebutuhan Fungsional}

\section{Tabel 1 Kebutuhan Fungsional}

\begin{tabular}{llc}
\hline No & Kebutuhan Fungsional & Keterangan \\
\hline 1 & Login & $\begin{array}{l}\text { Melakukan upaya menjalankan akses sistem } \\
\text { dengan hak akses yang telah di tentukan }\end{array}$ \\
\hline
\end{tabular}




\begin{tabular}{cll}
\hline 2 & $\begin{array}{l}\text { Manajemen Data Master } \\
\text { Admin }\end{array}$ & $\begin{array}{l}\text { Mengelola data GZ Studio Musik pada } \\
\text { sistem dengan fitur yang telah disediakan }\end{array}$ \\
\hline 3 & $\begin{array}{l}\text { Manajemen Data User/ } \\
\text { pelanggan }\end{array}$ & $\begin{array}{l}\text { Mengelola data admin pada sistem dengan } \\
\text { fitur yang telah disediakan }\end{array}$ \\
\hline 4 & Manajemen Laporan & $\begin{array}{l}\text { Mengelola data booking,laporan finansial/ } \\
\text { laporan keuangan. }\end{array}$ \\
\hline
\end{tabular}

Kebutuhan Non Fungsional

Tabel 2 Kebutuhan Non Fungsional

\begin{tabular}{clc}
\hline No & \multicolumn{1}{c}{ Deskripsi } & Nama \\
\hline 1 & $\begin{array}{l}\text { Cepat atau lambat aplikasi koneksi } \\
\text { database dan menampilkan ke Interface }\end{array}$ & Performa \\
\hline 2 & Kecepatan Akses internet & Accesibility \\
\hline 3 & Jenis Komputer yang di pakai & Specification \\
\hline 4 & $\begin{array}{l}\text { Sistem memiliki tampilan yang mudah } \\
\text { di fahami }\end{array}$ & Interface \\
\hline
\end{tabular}

Kebutuhan Sofware

Tabel 3 Kebutuhan Sofware

\begin{tabular}{cll}
\hline No & \multicolumn{1}{c}{ Nama Sofware } & \multicolumn{1}{c}{ Keterangan } \\
\hline 1 & Windows & Sebagai Sistem Operasi \\
\hline 2 & $\begin{array}{l}\text { Google Chrome dan Mozilla } \\
\text { Firefox }\end{array}$ & Web Browser \\
\hline 3 & XAMPP & Web Server \\
\hline
\end{tabular}

Kebutuhan Hardware

Tabel 4 Kebutuhan Hardware

\begin{tabular}{cll}
\hline No & \multicolumn{1}{c}{ Nama Hardware } & \multicolumn{1}{c}{ Deskripsi } \\
\hline 1. & Processor & $\begin{array}{l}\text { Minimal Processor Dual Core atau } \\
\text { lebih tinggi }\end{array}$ \\
\hline 2 & Harddisk & Harddisk Minimal $80 \mathrm{gb}$ \\
\hline 3 & $\begin{array}{l}\text { RAM (Random Access } \\
\text { Memory })\end{array}$ & RAM Minimal 2 gb \\
\hline 4 & Monitor/ LCD & Minimal LCD Monitor 14" \\
\hline 5 & Printer & Printer dengan berbagai jenis merk \\
\hline
\end{tabular}

Aktor yang terlibat

Tabel 5 Aktor Pada Sistem

\begin{tabular}{cll}
\hline No & \multicolumn{1}{c}{ Aktor } & \multicolumn{1}{c}{ Definisi } \\
\hline 1 & Admin/ Manajer & $\begin{array}{l}\text { Admin melakukan pengolahan data mastering } \\
\text { (Tambah,update dan hapus ) }\end{array}$ \\
\hline 2 & $\begin{array}{l}\text { Customer / } \\
\text { Pelanggan }\end{array}$ & $\begin{array}{l}\text { pelanggan melakukan proses pengisian data } \\
\text { diri, pemilihan jadwal booking serta melaukan } \\
\text { booking. }\end{array}$ \\
\hline
\end{tabular}




\section{Planning}

Perancangan desain sistem bertujuan memberikan gambaran kepada pengguna secara umum mengenai sistem yang dibangun.

Data Flow Diagram Level 0 (DFD Level 0 )

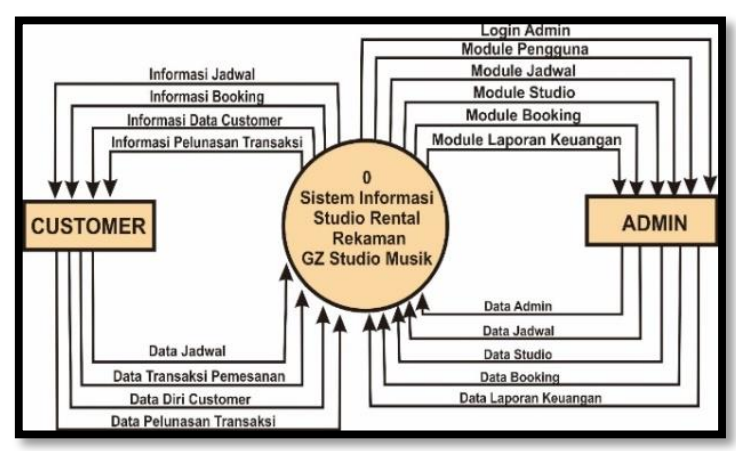

Gambar 2 Diagram Contexs

\section{Data Flow Diagram Lvl 1 (DFD Level 1)}

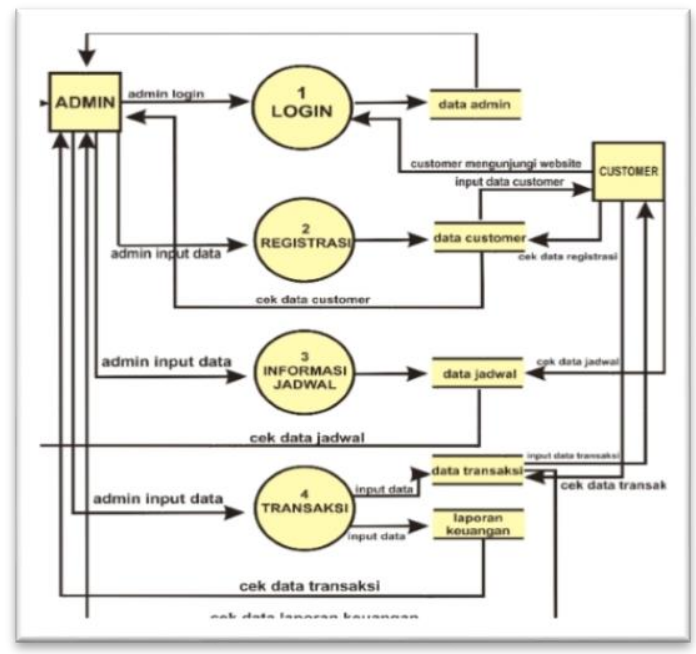

Gambar 3 dfd lvl 1

ERD

Pada sistem informasi Studio Rental Rekaman GZ Studio Musik Kepanjen - Malang ini terdapat beberapa tabel yang berelasi yang entitas-entitasnya saling berhubungan.

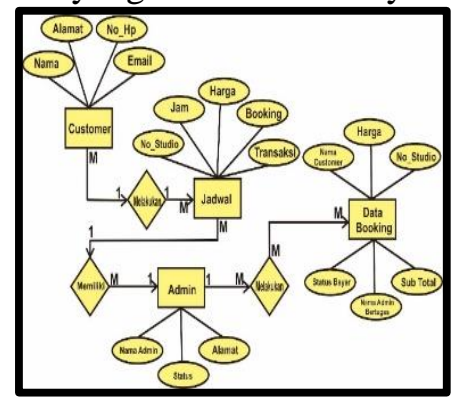

Gambar 4 Entity Relationship Diagram

\section{Conceptual Data Model}

Tabel CDM dalam pembangunan system informasi ini saling berelasi. Yang di dalamnya terdapat 5 tabel 


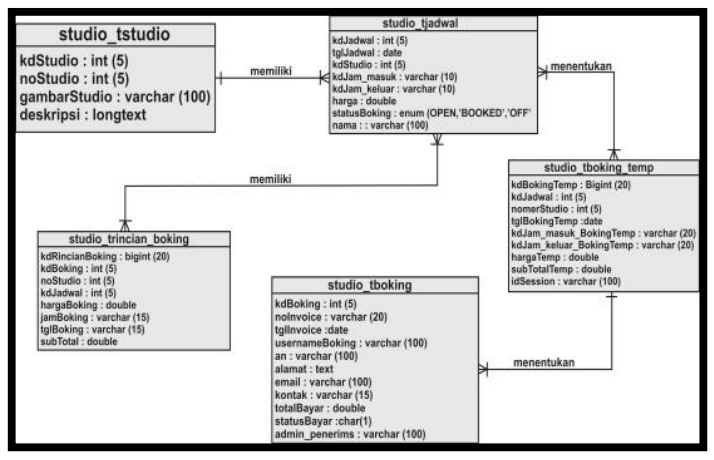

Gambar 5 Conceptual Data Model

PDM

CDM yang telah di buat selanjtnya di konversi menjadi Physical Data Model. Agar relasi antar table tampak jelas.

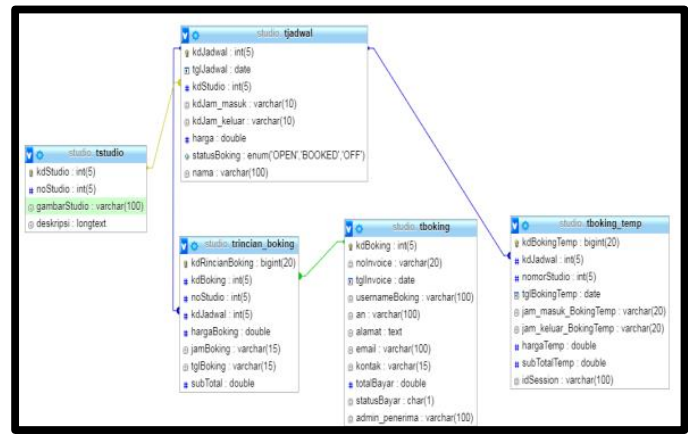

Gambar 6 Physical Data Model

\section{Modelling (Analiysis \& Design)}

Didalam membangun sebuah sistem tentunya sebuah rancangan sangat diperlukan agar saat proses pembuatannya bagi para pembuat program (programmer) dapat dengan mudah dalam pembuatan hasil akhirnya.

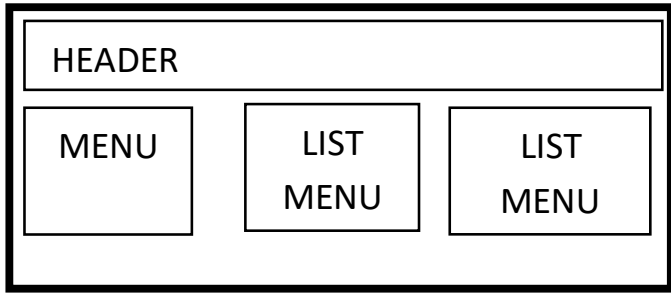

Gambar 7 rancangan interface List Ruang dan harga

\begin{tabular}{|c|c|}
\hline \multicolumn{2}{|l|}{ HEADER } \\
\hline $\begin{array}{c}\text { Data } \\
\text { Diri }\end{array}$ & Data Penyewa/ \\
& List Penyewa/ \\
\hline
\end{tabular}

\section{Gambar 8 Rancangan interface transaksi}

\section{Contruction ( Code and Test)}

Code

Potongan kode atau source code yang dibuat oleh peneliti yang menggunakan sublime text yang berperan penting dalam membuat fungsi-fungsi yang dibutuhkan. Source Code yang 
ditampilkan hanya sebatas menampilkan cara perhitungan metode yang diterapkan didalam sistem

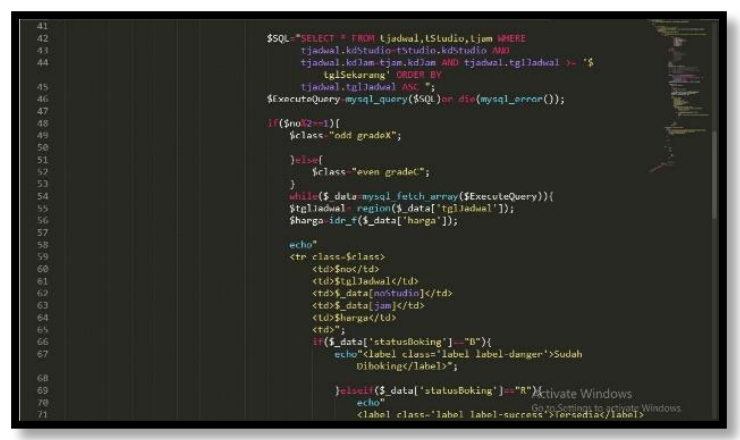

Gambar 8 Source Code

Test

Setelah tahap pemrograman selesai dilakukan kemudian dilakukan pengujian produk dengan blackbox testing.

Tabel 4.6 Pengujian Produk(Blackbox testing)

\begin{tabular}{|l|l|l|l|l|}
\hline No. & \multicolumn{1}{|c|}{ Fungsi } & \multicolumn{1}{|c|}{ Pengujian } & Hasil Yang Diharapkan & Ket \\
\hline 1. & $\begin{array}{l}\text { Form login } \\
\text { admin }\end{array}$ & $\begin{array}{l}\text { Masukan username } \\
\text { dan password }\end{array}$ & Masuk pada halaman utama & Sesuai \\
\hline 2. & $\begin{array}{l}\text { Master } \\
\text { Admin }\end{array}$ & $\begin{array}{l}\text { Pilih menu Admin } \\
\text { tekan simpan, ubah } \\
\text { dan hapus data }\end{array}$ & $\begin{array}{l}\text { Menampilkan data Admin } \\
\text { dan menyimpan perubahan } \\
\text { data ke database }\end{array}$ & Sesuai \\
\hline 3 & $\begin{array}{l}\text { Master } \\
\text { Customer }\end{array}$ & $\begin{array}{l}\text { Pilih Ruang/ studio } \\
\text { Booking,Jadwal, dan } \\
\text { Harga } \\
\text { Transaksi, } \\
\text { Pembayaran } \\
\text { henampilkan ruangan dan }\end{array}$ & Sesuaiatan Booking \\
\hline 4 & $\begin{array}{l}\text { Login } \\
\text { customer/ } \\
\text { Pelanggan }\end{array}$ & $\begin{array}{l}\text { Pilih menu, isi data } \\
\text { diri }\end{array}$ & $\begin{array}{l}\text { Menampilkan data diri } \\
\text { pelanggan }\end{array}$ & Sesuai \\
\hline
\end{tabular}

\section{Deployment}

Adalah tahap sistem siap digunakan,nantinya dapat diketahui apabila sistem yang telah dibuat memang sudah sesuai dengan yang direncanakan.

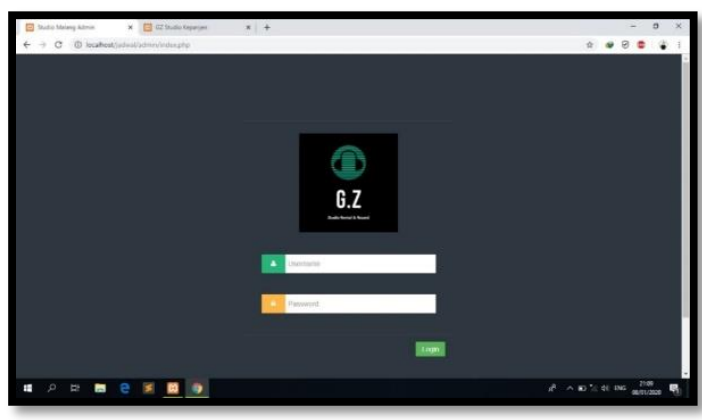

Gambar 9 Tampilan login admin 


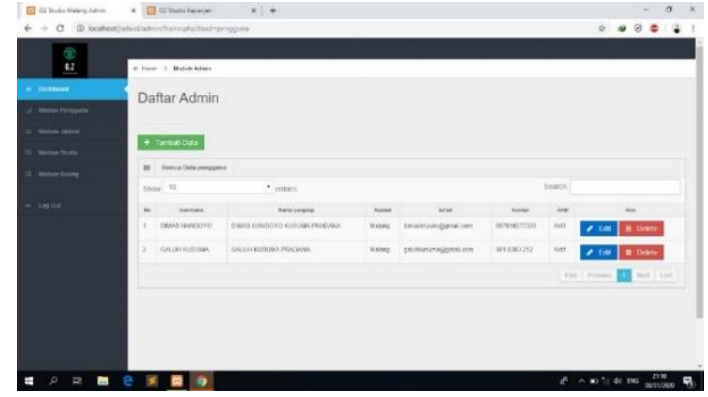

\section{Gambar 10 Tampilan sistem master admin}

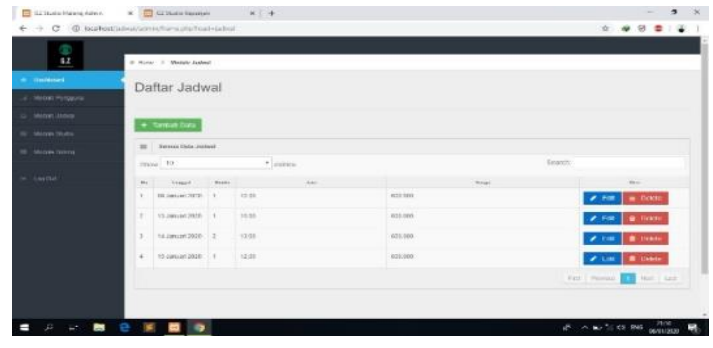

Gambar 11 Tampilan sistem Penjadwalan

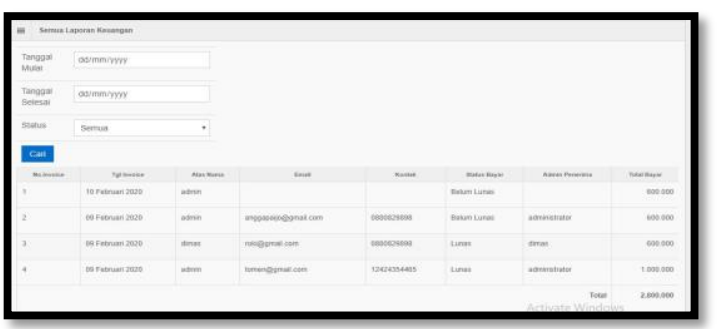

Gambar 12 Tampilan laporan keuangan

\section{Pembahasan Produk}

Sistem Booking melalui Website yang di rancang untuk GZ Studio Musik Kepanjen Kabupaten Malang adalah sistem yang berjalan secara serverside. Setelah hasil rancang bangun selesai dibuat serta diuji coba, maka selanjutnya dilakukan pengujian User Acceptance Test $(U A T)$ yang melibatkan 30 responden. Pengujian tersebut menggunakan angket yang memiliki penilaian 3 aspek yang meliputi aspek sistem, aspek pengguna, dan aspek interaksi.

Pengujian yang dilakukan aspek sistem mendapatkan nilai $89 \%$, aspek pengguna mendapatkan nilai $90,6 \%$ sedangkan aspek interaksi mendapatkan nilai 91,45\%. Setelah dihitung rata-rata keseluruhan mendapatkan hasil presentase kelayakan mencapai $90.35 \%$.

\section{PENUTUP}

\section{Kesimpulan}

Berdasarkan hasil dari pengujian UAT dan black box melalui penyebaran quesioner dapat disimpulkan bahwa Sistem Informasi Studio rental Rekaman GZ Studio Musik Berbasis Web ini dapat menyajikan informasi yang akurat dan memudahkan pengguna mengolah data yang mengenai pemesanan dan penyewaan alat studio secara daring, ditingkatkannya layanan terhadap konsumen dan serta pemasaran. 


\section{Saran}

Sistem infomasi ini disarankan untuk terus dikembangkan guna menyesuaikan dengan kebutuhan dari pengguna sistem yang terus bertambah.

\section{DAFTAR PUSTAKA}

Ladjamudin, bin Al-Bahra.2013. Analisis dan Desain Sistem Informasi. Yogyakarta: Graha Ilmu.

Agus Mulyanto.2009. Sistem Informasi Konsep dan Aplikasi. Yogyakarta:Pustaka Pelajar.

Kadir,Abdul 2003. Pengenalan Komputer, Dasar Ilmu Komputer dan Pemrograman Sistem Informasi.Yogyakarta: Penerbit ANDI.

Yakub.( 2012). Pengantar Sistem Informasi. Yogyakarta:Graha Ilmu.

Kristanto,Andri. 2008. Perancangan Sistem Informasi dan aplikasinya.Yogyakarta: Gava Media.

Sadeli, Muhammad.2013.Dreamweaver CS6 untuk orang Awam. Palembang:Maxikom

Handayaningrat, Soewarno. 1992. Pengantar Studi Ilmu Administrasi dan Manajemen. Jakarta:Cv Haji Masagung

Ariani Sukamto, R.,\& Shalahuddin,M. 2016. Rekayasa Perangkat Lunak (Informatik).Bandung.

Alfian, Budi. 2011. "Analisa Perancangan Sistem Billing dan Booking di PT. COMET POOL \& LOUNGE”.Jurnal.

Pamungkas, Lingga. 2012."Perancangan Sistem Informasi Penyewaan VCD/DVD Pada Ultra Disc Ciamis". Skripsi Sarjana Komputer. Universitas Komputer Indonesia Bandung 